\title{
Analisis Kurva Kalibrasi Colorimeter Sederhana Penentuan Ammonium pada Sampel Pupuk NPK
}

\author{
Yohan \\ Program Studi Teknik Mesin, Universitas Pamulang, Jl. Surya Kencana No. 1, Tangerang Selatan, Indonesia \\ E-mail: dosen01358@unpam.ac.id
}

Masuk : 5 April 2020

Direvisi : 25 April 2020

Disetujui : 5 Mei 2020

\begin{abstract}
Abstrak: Colorimeter memiliki fungsi yang baik dan mudah untuk mendeskripsikan kadar ammonium pada pupuk. Ammonium merupakan unsur yang penting pada pupuk dikarenakan sifatnya yang mudah menguap pada temperatur ruang sehingga mengurangi fungsi pada pupuk tersebut. Analisis kurva kalibrasi diperlukan untuk mengurangi nilai bias metode pengukuran sehingga dapat diketahui rentang konsentrasi analisis ammonium yang kredibel. colorimeter ini digunakan untuk menguji sampel tertentu yang berorientasi pada analisis kualitatif dan kuantitatif pengukuran warnanya. Colorimeter dirancang berdimensi $(10 \times 10 \times 8) \mathrm{cm}^{3}$ yang terbuat dari bahan fiberglass dengan menggunakan sumber cahaya panjang gelombang $467 \mathrm{~nm}$ dengan irradiasi $0,141 \mathrm{~W} / \mathrm{m}^{2}$. Analisis pada colorimeter sederhana ini didapatkan nilai terbaik pada pengukuran menggunakan analit ammonia menghasilkan persamaan dengan koefisien korelasi 0,971 dan konsentasi terbaik yang terdeteksi 1,5 ppm, sedangkan untuk konsentrasi optimal berkisar 2 ppm. Pada Colorimeter Sederhana ini memiliki akurasi dan presisi sebesar 99,8 \% dan 88,7\%.Data-data pengukuran tersebut menunjukkan bahwa Colorimeter sederhana ini dapat digunakan sebagai alat pengukuran pupuk NPK pada konsentrasi $1,5 \mathrm{ppm}$.
\end{abstract}

Kata kunci: Ammonium, Spektrofotometer, Colorimeter, Arduino, dye.

\begin{abstract}
A colorimeter is very useful and easy to describe the ammonium content in a fertilizer. Ammonium is an important element in fertilizers due to its volatile nature at room temperature, thereby reducing its function. Calibration curve analysis is needed to reduce the bias value of the measurement method so that a credible ammonium analysis concentration range can be found. This colorimeter is used to test certain samples that are oriented towards qualitative and quantitative analysis of their color measurement. The colorimeter is designed with dimensions $(10 \times 10 \times 8) \mathrm{cm} 3$ made of fiberglass using a light source with a wavelength of $467 \mathrm{~nm}$ with irradiation of $0.141 \mathrm{~W} / \mathrm{m} 2$. The analysis on this simple colorimeter gets the best value for measurements using an ammonia analyte to produce an equation with a correlation coefficient of 0.971 and a concentration. the best is detected $1.5 \mathrm{ppm}$, while the optimal concentration ranges from $2 \mathrm{ppm}$. This simple colorimeter has an accuracy and precision of $99.8 \%$ and $88.7 \%$. These measurement data indicate that this simple colorimeter can be used as a measuring tool for NPK fertilizer at a concentration of $1.5 \mathrm{ppm}$.
\end{abstract}

Keywords: Ammonium, Spectrophotometer, Colorimeter, Arduino, dye.

\section{PENDAHULUAN}

Colorimeter merupakan instrumen penting dalam analisis kimia. Instrumen ini digunakan untuk menguji sampel tertentu yang berorientasi pada pengukuran kualitatif dan kuantitatif. Oleh karena itu instrumen ini penting digunakan pada sektor pendidikan, penelitian, maupun industri. Pada sektor pertanian alat ini sebagai media untuk menguji unsur-unsur hara pada tanah dan pupuk. Pada sektor penelitian berperan dalam menguji analisis senyawa secara kuantitatif dan kualitatif pada sampel. Pada sektor industri alat ini berperan untuk menentukan kadar bahan yang digunakan pada industri dyes dan analisis kadar senyawa pada limbah yang dihasilkan. Namun untuk pemenuhan alat ini, negara Indonesia masih mengimport dari negara lain. Oleh karena itu, kami berproyeksi mengembangkan colorimeter untuk penentuan ammonium pada pupuk. Yohan dan Fifit 
telah berhasil membuat rancangan spektrofotometri berdasarkan arduino uno dengan menggunakan sumber cahay dengan panjang gelombang $467 \mathrm{~nm}[13]$. Pada penelitian ini akan dilakukan penggunaan panjang gelombang $520 \mathrm{~nm}$ untuk mengembangkan alat colorimeter dari spektrofotometer yang dapat digunakan untuk petani-petani lokal sehingga dapat menjaga kualitas pupuknya dan terhindar dari perdaran pupuk palsu ataupun tidak standar.

\section{METODOLOGI}

\section{Peralatan}

Spektrofotometer UV-Vis, labu ukur $25 \mathrm{~mL}$, botol pot plastik $50 \mathrm{cc}$, Gerinder RYU RSG1000-1, Mesin Bor Makita 6412, molding sheet, Mesin CNC laser 1325.

\section{Bahan}

Pupuk NPK,akuabides, kuvet, LED, LDR, Power supply 24 watt, Kabel, resin fiberglass, silikon rubber RTV, Seven segmen TM 74HC595, Arduino.

\section{Perancangan Colorimeter Sederhana}

Perancangan digambar dengan menggunakan aplikasi sketchup. Colorimeter dirancang dengan sistem doble beam radiasi cahaya yang sebelumnya telah dibuat oleh Gong, dkk, $2009^{[5]}$.

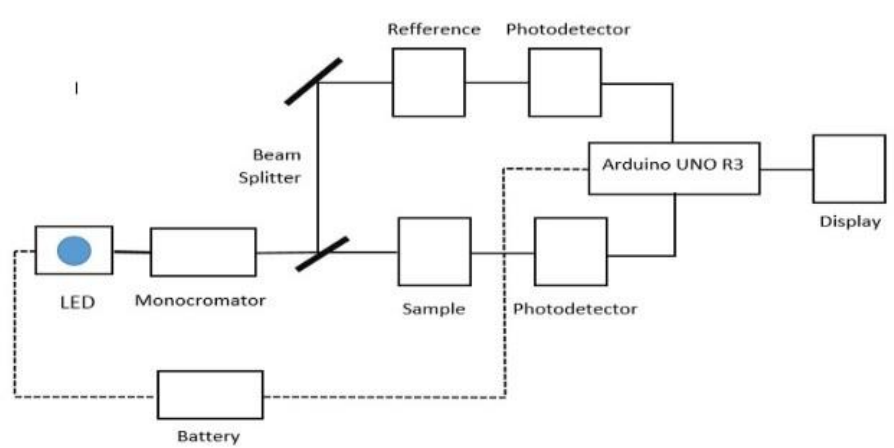

Gambar 1. Desain Sistem Bagan Colorimeter sederhana $467 \mathrm{~nm}$.

\section{Pembuatan Colorimeter sederhana}

Rangka Colorimeter ber dibuat berdasarkan pembuatan spektrofotometer edukasi yang telah dirancang oleh yohan \& fifit pada tahun 2017 yang memiliki dimensi $(10$ x 10 x 6,5 $) \mathrm{cm}^{3}$ yang memiliki sumber radiasi sebesar $0.141 \mathrm{~W} / \mathrm{m}^{2}$ dengan panjang gelombang $467 \mathrm{~nm}$. Colorimetersederhana didisain secara portabel terdiri dari rangakian arduino, sensor photometer, Pemprograman menggunakan software arduino 1.8.5, dan baterai Lithium dengan daya $9 \mathrm{~V}$.

\section{Pengujian kuantitatif}

Uji kuantitatif dilakukan dengan membuat larutan standar masing-masing konsentrasi $0,0,1,1,1,5$, dan 2 ppm ammonium Setelah itu ditentukan kurva kalibrasi. 


\section{HASIL DAN PEMBAHASAN}

\section{Colorimetri kits}

Perancangan colorimeter digambar dengan menggunakan software sketchup drawing. Colorimeter terdiri dari kotak sumber cahaya, dudukan kuvet referensi dan sampel, plug daya, saklar dan pengatur daya sumber cahaya. Colorimeter didisain dengan sistem doubel beam yang terdiri dari pengukuran referensi dan sampel. Pada colorimeter didukung dengan peralatan evaporator dan reagen nessler. Evaporator bertujuan untuk memisahkan ion logam dengan ammonium sedangkan reagen nessler berfungsi sebagai zat pewarna kuning pada saat berikatan dengan ammonium.

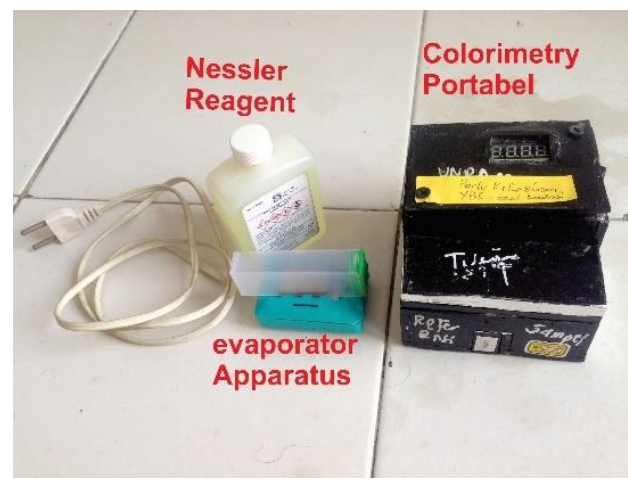

Gambar 2. Colorimeter sederhana dan peralatan pendukung untuk penentuan ammonium pada pupuk NPK.

.Pembuatan Colorimeter sesuai dengan sistem doubel beam. Colorimeter ini terdapat alat pendukung yaitu evaporator yang digunakan untuk pemisahan antara ion logam dengan ammonium, dan reagent nessler yang berfungsi sebagai zat pewarna yang memberikan warna kuning. Kotak Sumber Cahaya dibuat dengan dimensi $1,9 \mathrm{~cm} \times 2,5 \mathrm{~cm} \times 2,5 \mathrm{~cm}$ dengan ketebalan $5 \mathrm{~mm}$ yang terbuat dari bahan fiberglass dan pewarna hitam agar mengurangi inteferensi cahaya dari luar. Kotak Sumber cahaya memiliki diameter lubang cahaya sebesar $2 \mathrm{~mm}$.

\section{Uji kuantitatif menggunakan Colorimeter sederhana dan Analisis kurva kalibrasi}

Uji kuantitatif dilakukan untuk mengetahui konsentrasi analit pada larutan. Pada penentuan ammonium pada pupuk NPK dibuat larutan standar ammonium dengan konsentrasi 0-2 ppm. Uji kualitatif dilakukan dengan mengoperasikan Colorimeter sederhana dengan panjang gelombang sumber cahaya $467 \mathrm{~nm}$. Hasil pengukuran ditunjukkan pada Tabel 1. sebagai berikut.

Tabel 1. Hubungan konsentrasi ammonium terhadap absorbansi $467 \mathrm{~nm}$ menggunakan Colorimeter sederhana.

\begin{tabular}{ccc}
\hline No & Konsentrasi & Absorbansi \\
\hline 1 & 0.1 & 0.095 \\
2 & 0.5 & 0.103 \\
3 & 1 & 0.109 \\
4 & 1.5 & 0.125 \\
5 & 2 & 0.14 \\
\hline
\end{tabular}

Pada hasil menunjukkan colorimeter dapat memberikan respon kenaikan nilai absorbansi dengan kenaikan konsentrasi analit sehingga dapat dibentuk kurva kalibrasi dengan persamaan yang didapatkan nilai terbaik $\mathrm{y}=0,0234 \mathrm{x}+0,0905$, dengan regresi linieritas sebesar 0,9716 . 


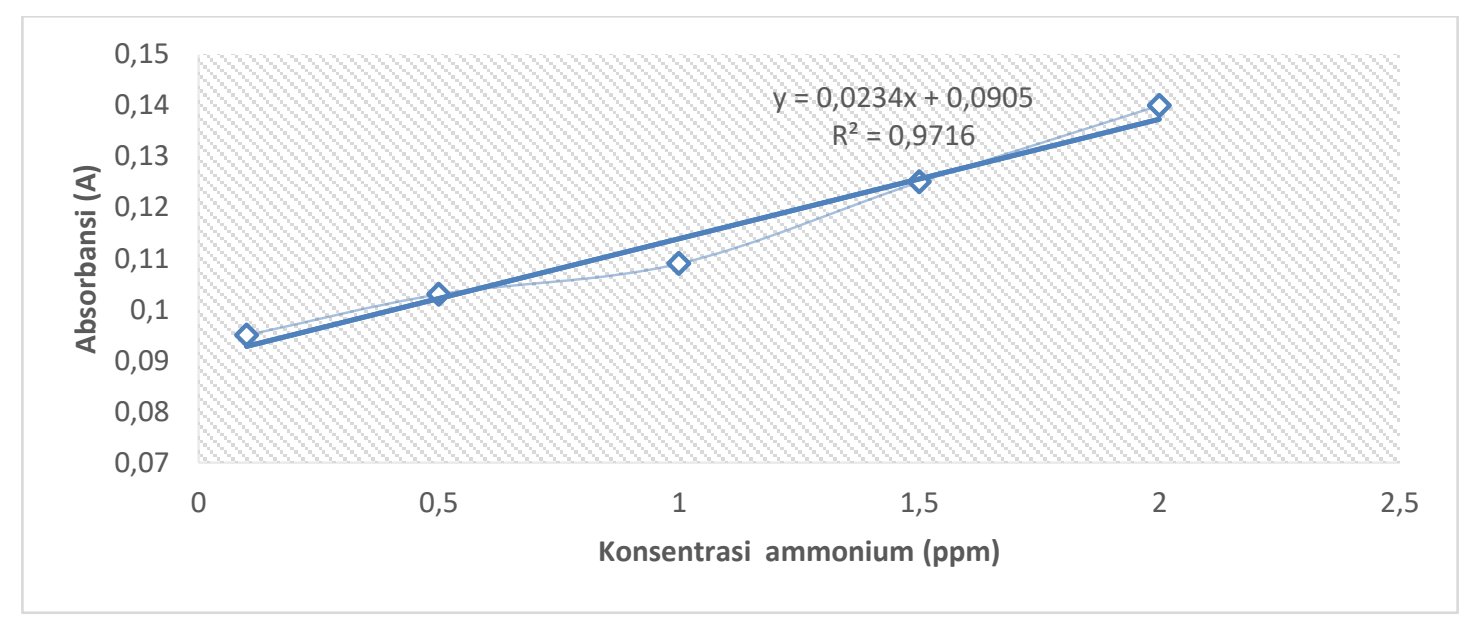

Gambar 3. Grafik kurva kalibrasi pengukuran konsentrasi ammonium dengan Colorimeter $520 \mathrm{~nm}$ dengan konsentrasi 0-2 ppm dengan nilai intersept 0.0905 .

Menurut Calcutt.,dkk pada tahun 1982., kalibrasi dapat dilakukan melalui penyesuian garis linier sebenarnya. Pada pengukuran menggunakan metode lambert beer menyatakan hubungan antara absorbansi dan konsentrasi membentuk garis lurus seperti pada Gambar 4 dibawah ini.

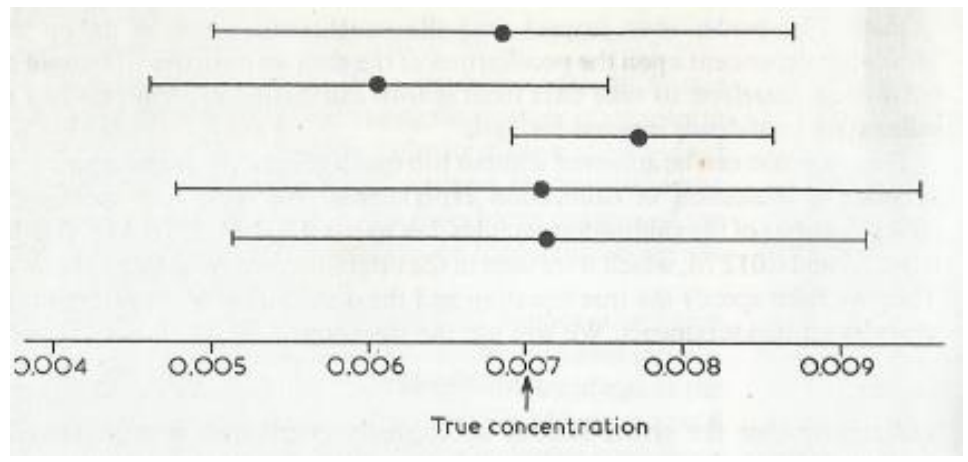

Gambar 4. Interval pengukuran untuk mendapatkan konsentrasi sebenarnya membentuk garis lurus.

Perhitungan absorbasi dilakukan dengan menggunakan persamaan 1 dan 2 berdasarkan hukum lambertbeer. Pada uji ini dihasilkan persamaan $y=0,0234 x+0,0905$ dengan koefisien korelasi 0,9716 . Sehingga untuk mendapatkan nilai sebenarnya melalui menarik garis lurus pada kalibrasi kurva dengan $\mathrm{db}=5$, rentang kepercayaan 95\%, $\mathrm{t}=2,57$ menghasilkan rentang kepercayaan intersept yaitu $-0,0110$ sampai 0,0358 dan rentang kepercayaan slope yaitu $-0,0112$ sampai 0,1065 dan memiliki nilai RSD 0,0408. Batas konsentasi terendah yang dilakukan dan yang terdeteksi dilakukan secara pengukuran menggunakan Colorimeter sebesar $0.1 \mathrm{ppm}$ dan tertinggi yang direkomendasikan untuk meningkatkan transmittansi adalah $2 \mathrm{ppm}$. Berikut grafik kurva kalibrasi colorimeter penentuan amminium melalui garis lurus titik nol menghasilkan persamaan $\mathrm{y}=0,0849 \mathrm{x}$ sehingga menghasilkan Tabel 2. 
Tabel 2. Analisis nilai absorbansi sebenarnya pada penentuan ammonium terhadap absorbansi $467 \mathrm{~nm}$ menggunakan Colorimeter sederhana.

\begin{tabular}{cccc}
\hline No & Konsentrasi & Absorbansi & Absorbansi sebenarnya \\
\hline 1 & 0.1 & 0.095 & 0.0084 \\
2 & 0.5 & 0.103 & 0.0424 \\
3 & 1 & 0.109 & 0.0848 \\
4 & 1.5 & 0.125 & 0.1273 \\
5 & 2 & 0.14 & 0.1697 \\
\hline
\end{tabular}

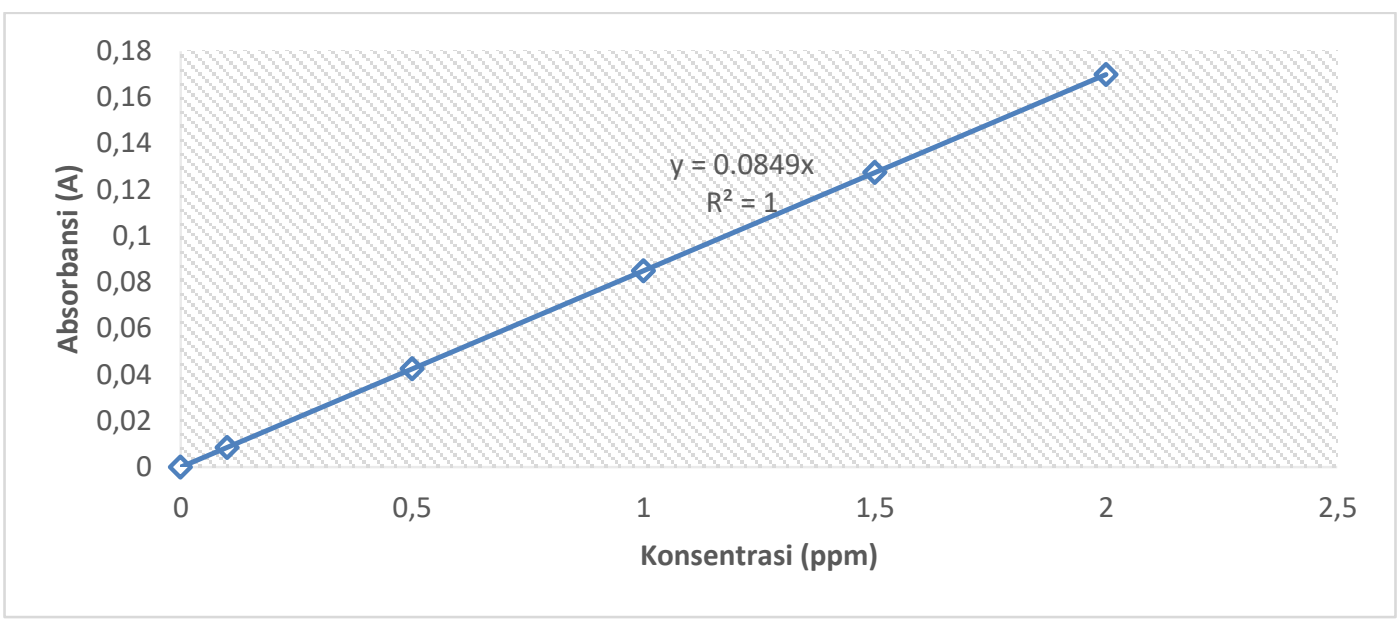

Gambar 5. Grafik kurva kalibrasi pengukuran konsentrasi ammonium dengan Colorimeter $520 \mathrm{~nm}$ dengan konsentrasi 0-2 ppm dengan nilai intersept 0 .

Pada hasil Analisis kalibrasi kurva didapat nilai absorbansi sebenarnya untuk batas pengukuran didapat nilai minimum pengukuran pada konsentrasi 1 ppm sampai 2 ppm. Pada penentuan nilai presisi dilakukan enam kali perulangan pengukuran sehingga didapatkan nilai presisi 88,7 \% dan untuk nilai akurasi dilakukan menggunakan larutan standar dengan menggunakan konsetrasi 1,5 ppm dengan enam kali perulangan sehingga didapatkan nilai akurasi 99,8\%.

\section{KESIMPULAN}

Colorimetri Sederhana portabel dirancang berdimensi $10 \mathrm{~cm}$ x $10 \mathrm{~cm}$ x $8 \mathrm{~cm}$ yang terbuat dari bahan fiberglass dengan menggunakan sumber cahaya dengan panjang gelombang $467 \mathrm{~nm}$ yang memiliki sistem doble beam yaitu memiliki pengukuran referensi dan sampel yang diharapkan dapat dipergunakan untuk petani dalam menganalisis pupuk NPK. Pada Analisis nilai absorbansi sebenarnya melalui penyesuaian linieritas kurva kalibrasi didapat nilai persamaan linieritas percobaan $\mathrm{y}=0,0234 \mathrm{x}+0,0905$ dengan nilai regresi liniritas 0,9716 yang kemudian disesuaikan menjadi persamaan $\mathrm{y}=0,0849 \mathrm{x}$. Uji linearitas pada colorimeter sederhana ini didapatkan nilai terbaik pada pengukuran menggunakan analit (ammonium) pada konsentrasi $1,5 \mathrm{ppm}$ yang memiliki akurasi dan presisi sebesar $99,8 \%$ dan $88,7 \%$.

\section{UCAPAN TERIMAKASIH}

Penulis menucapkan terimakasih kepada Kemenristek Dikti atas bantuan pendanaan progam hibah PDP 2019. 


\section{DAFTAR PUSTAKA}

[1] Rupali, V.K., Ashok D.K. 2013.Colorimetry based calcium measurement. International Journal of Engineering Research and Development . 7 , 08-11.

[2] Fathima, S.,Dhammika, D., Paul, D., and Andrew, D.2010. A modified low-cost colorimetric method for paracetamol(Acetaminophen) measurement in plasma. Journal of the Royal Society of Medicine . Clinical Technology48, 42-46.

[3] Marie, H., Ivan, S., and Hana, S. 2011. Colour analysis and discrimination of laboratory prepared pasta by means of spectroscopic methods. Czech Journal Food Sciences. 29(4): 346-353.

[4] Heonsang, J., C., Jongtaek, P., and Hyunook, K. 2013. Determination of NH+ in environment water with interfering substance using the modified nessler method. Journal of chemistry ID 359217,1-9.

[5] Yohan, y., Fifit, A., Adimas, W. 2018. Pembuatan Spektrofotometer Edukasi Untuk Analisis Pewarna Makanan.Chimica et Natura Acta. 6(3):111-115.

[6] Cazes, J. 2005. Ewing's Analytical Instrumentation Handbook, 3th edn. Marcel Dekker, NewYork.

[7] Caulcutt, R., and Boddy, R 1983. Statistics for Analytical Chemists.Chapman and Hall, London.

[8] Daniel, C.H. 2010. Quantitative Chemical Analysis, 8 th edn, W.H. Freeman and Company, New York. 